“ (C) 2013 IEEE. Personal use of this material is permitted. Permission from IEEE must be obtained for all other uses, in any current or future media, including

reprinting/republishing this material for advertising or promotional purposes, creating new collective works, for resale or redistribution to servers or lists, or reuse of any copyrighted component of this work in other works." 


\title{
Improved Direct Torque Control Method of Brushless Doubly-Fed Reluctance Machines for Wind Turbine
}

\author{
William K. Song and David G Dorrell \\ School of Electrical, Mechanical and Mechatronic Systems \\ University of Technology, Sydney \\ Sydney, NSW, Australia \\ William.K.Song@student.uts.edu.au and David.Dorrell@uts.edu.au
}

\begin{abstract}
Direct Torque Control (DTC) method is an excellent technique for torque and flux control for a brushless doubly-fed reluctance machine (BDFRM). The advantages of the DTC method are simple implementation, fast response and little dependence on the machine parameters. However, the conventional DTC method has high torque and flux ripple and variable switching frequency problems. This paper proposes an improved DTC method for the BDFRM when used in wind power generation systems. The Space Vector Modulation (SVM) method is used for reducing the torque and flux ripple, and also for holding constant the switching frequency of the inverter. The control method is implemented in SIMULINK $® / M A T L A B \circledR$ and the results show that the proposed DTC method can overcome the issues and problems associated with the conventional DTC method and improve the system operation performance.
\end{abstract}

Keywords-DTC; BDFRM; Wind Turbine; Simulation; brushless doubly-fed reluctance machine

\section{INTRODUCTION}

In recent years, the brushless doubly-fed reluctance machine (BDFRM) has been researched. This is one of a family of slip power recovery machines are being used or investigated for renewable energy applications [1]. They can operate in several different modes but one is as a slip energy machine similar to the doubly-fed induction generator (DFIG) that is now very common in wind turbines. The BDFRM has no brushes which is an advantage over the DFIG. It also has high power density and efficiency as illustrated in [2]. The machine has two sets of 3-phase windings in the stator. One is connected directly to the grid and one is connected to grid via a bidirectional inverter. Because the machine only requires a partially rated converter it is possible to reduce the cost of the drive system and the brushless nature of the machine increases its reliability. This is especially beneficial in large power applications such as wind turbines and large pumps. Therefore various control methods for the BDFRM have been investigated [3][4].

The Direct Torque Control (DTC) method is one of several different drive control methods. It is considered to be one of the most high performance BDFRM drive control strategies [5][6]. It offers simple implementation and fast torque response, as well as better speed control and little dependence on the machine parameters. This reduces the hardware drive cost when compared to vector controlled drives. However, the conventional DTC strategy produces high torque and flux ripple, current harmonics, variable switching frequency and low performance during transient torque periods. This is because of the use of a switching table selection method.

This paper proposes an improved DTC method for controlling the BDFRM when it is incorporated into a wind power generation system. In a divergence from the conventional DTC method, the improved DTC method is implemented using a Space Vector Modulation (SVM) technique. This reduces torque and flux ripple and current harmonics [7][8]. The proposed method provides low torque and flux ripple and constant switching frequency and also gives good performance during transient torque periods. Simulation results are put forward in this paper which illustrate that the improved DTC method reduces torque and speed ripple considerably.

\section{THEORY OF OPERATION}

For high efficiency control of the BDFRM, the conventional DTC method is a successful technique for driving the machine. This method has a fast and accuracy response because it utilizes torque and flux independently. It can also control the switching frequency by controlling the hysteresis bandwidth. This method can be implemented using simple control hardware; hence it can reduce the hardware cost too.

However, this method does have some disadvantages such as high torque and flux ripple, current harmonics and low performance during torque transient periods because it uses a switching table selection method. Furthermore, this method has to increase the sampling frequency and inverter switching frequency. The varying inverter switching frequency makes it difficult to design filters for the converter.

Fig. 1 shows a block diagram of the proposed DTC method in this paper. Instead of the switching table selection method in the traditional DTC, this paper proposes the use of an SVM module. This PWM module is a well-known technique for reducing current harmonics and torque and flux ripple. It also provides fixed frequency control of the inverter. The control block consists of a speed sensor for detecting the BDFRM speed, the flux and torque calculator, and the SVPWM selector. These replace the hysteresis controllers and switching table. The power block consists of the primary power supply, DC rectifier, 2-level inverter and BDFRM. 
In Fig. 1, the reference torque $T_{\mathrm{e}}{ }^{*}$ can be obtained from the difference between the reference speed $\omega_{r m}{ }^{*}$ and the feedback speed $\omega_{r m}$. The torque difference $\Delta T_{\mathrm{e}}$ can be similarly obtained from the difference between the reference torque $T_{\mathrm{e}}{ }^{*}$ and the estimated torque $T_{\mathrm{e}}$. The q-axis voltage $v_{\mathrm{qs}}$ can be obtained from the PI controller of the torque difference $\Delta T_{\mathrm{e}}$. The d-axis voltage $v_{\mathrm{ds}}$ is obtained in a similar fashion from the flux PI controller where the flux difference $\Delta \lambda_{\mathrm{s}}$ is the difference between the reference $\lambda_{\mathrm{s}}{ }^{*}$ and estimated $\lambda_{\mathrm{s}}$. The space voltage vectors can be calculated and selected using $v_{\mathrm{ds}}$ and $v_{\mathrm{qs}}$; these are used to control the flux and torque of the machine. The flux angle $\theta$ can be estimated from the flux calculator module. Finally, the inverter switching signals are generated by the SVPWM module, and these are used to control the 2-level inverter to drive the BDFRM.

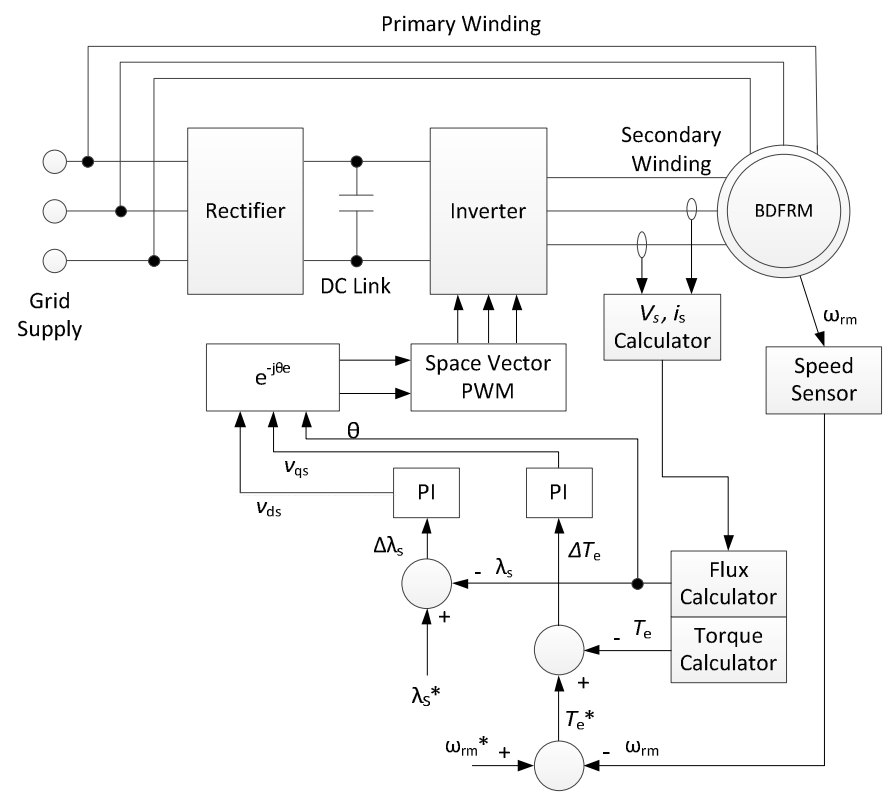

Fig. 1. Control block diagram of the improved DTC method.

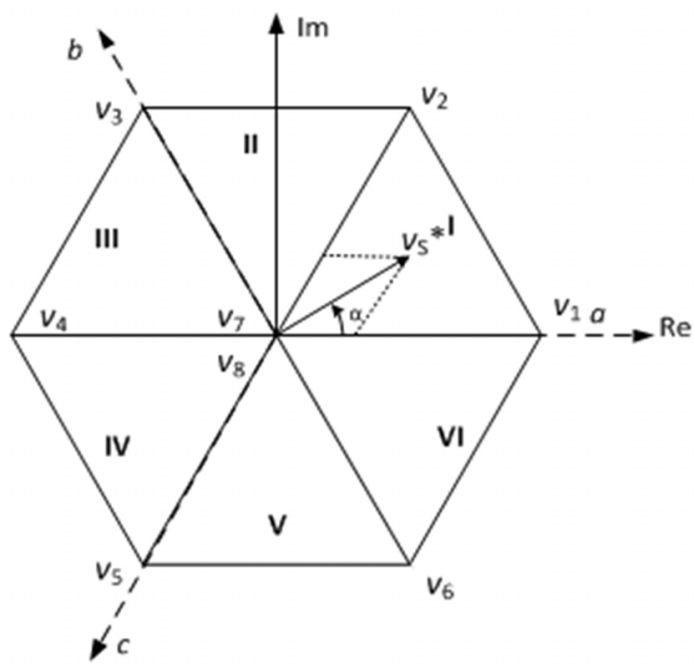

Fig. 2. Representation of space voltage vectors.

\section{OPERATION OF SPACE VECTOR MODULATION}

Fig. 2 illustrates the representation of the space voltage vectors. The SVPWM can obtain all the reference voltage vectors which are formed from the sum of two non-zero output voltage vectors and a zero output voltage vectors. For example, when a reference voltage vector is in Sector I, the reference voltage vector can be formed from the sum of vector $v_{1}$, vector $v_{2}$ and a zero vector $\left(v_{7}\right.$ or $\left.v_{8}\right)$. Thus, this is represented by

$$
\int_{0}^{T_{S}} v_{S}^{*} d t=\int_{0}^{T_{1}} v_{n} d t+\int_{T_{1}}^{T_{1}+T_{2}} v_{n+1} d t+\int_{T_{1}+T_{2}}^{T_{S}} v_{0} d t
$$

where $v_{\mathrm{s}}^{*}$ is the reference voltage vector, $T_{\mathrm{s}}$ is the sampling time, $T_{1}$ and $T_{2}$ are periods of the application of $v_{n}$ and $v_{n+1}$, and $v_{0}$ is the zero vector.

For minimization of the current harmonics and torque ripple, the symmetry space vector pulse width modulation method is the best switching technique. The zero voltage vector is applied in the first period then two non-zero voltage vectors are applied. Finally, the zero voltage vector is applied again. This method is shown on Fig. 3. This allows the switching frequency to be reduces. When the space voltage vector is changed in the sequence $V_{0}(000) \rightarrow V_{1}(100) \rightarrow V_{2}(110) \rightarrow V_{7}$ (111), then only one switching operation is required.

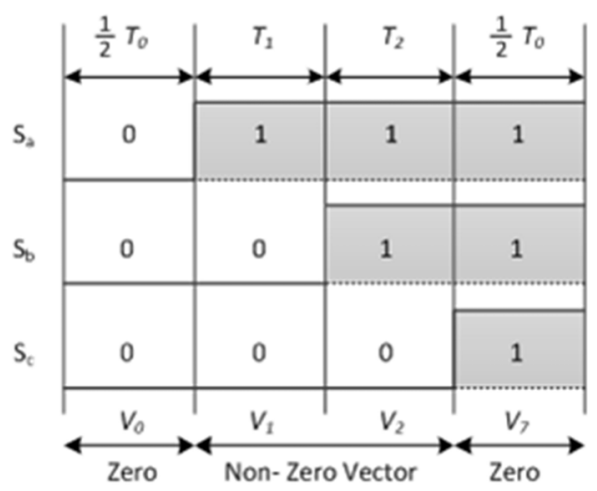

Fig. 3. The applying sequence of space voltage vector.

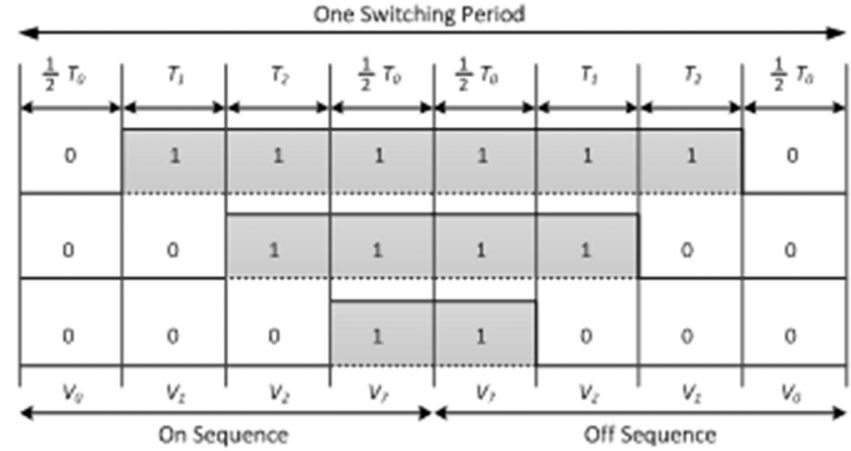

Fig. 4. The continuous voltage modulation switching. 
One switching period is consists of an ON sequence and an OFF sequence. This method can provide the minimum switching time. Therefore $2 T_{S}$ is one switching period of one power transistor. In this method, all three phase power transistors will be switched in one switching period, so this method is called continuous voltage modulation. The switching sequence for this is shown in Fig. 4.

\section{Simulation Module OF BDFRM}

The flux in the BDFRM is important. The ducted or salient pole rotor will modulate the MMF in the 3-phase windings and produce cross linkage. When the machine has good flux paths and good coupling it may have high efficiency and torque density. Recently attention has been paid to making better flux paths between the stator windings using a ducted rotor [9]. The pole numbers between the stator windings and rotor can vary. In [2] 4 and 6 pole windings were used with a 5 pole winding (4-6-5). While producing good coupling and operating with high efficiency this can give high unbalanced magnetic pull. Other common arrangements use 2 and 6 pole windings with a 4 pole rotor (2-6-4) and 4 and 8 pole windings with a 6 pole rotor (4-8-6). An example cross section arrangement of a 2 and 6 pole windings machine with a 4 pole ducted rotor is given in Fig. 5. Here we will be using specification similar (but not identical) to a small example of a 2-6-4 machine as reported in [9] and used by Betz in several earlier papers on control of the BDFRM. However it should be stated that more lately the 4-86 is being developed. The reason for this is that it does not suffer from unbalanced magnetic pull like the 4-6-5 arrangement and does not have cross-coupling issues due to saturation like the 2-6-4 arrangement.

Using some basic parameters as given in Table I then the machine was simulated. The inertia is very low. This is to test the robustness of the control. Further work will obviously simulate the machine with real parameters and implement the control on a real machine which is currently under construction and test. The inertia of the system can be somewhat more difficult to assess than it may first appear. When connecting to a wind turbine then there may be a gearbox and the actual turbine itself to incorporate, including the blades.

With an arbitrary low inertia of $0.005 \mathrm{Kgm}^{2}$ then a change in speed of $100 \mathrm{rpm}(10.47 \mathrm{rad} / \mathrm{s})$ in $0.005 \mathrm{~s}$ (this is really servo drive reaction times) the torque required is $10.5 \mathrm{Nm}$. However, this is only to test the control strategy and the control will have a finite reaction time which is fast. A low inertia will allow examination of this reaction time and control. The actual inertia with generator, gearbox, turbine hub and blades will be much higher. The results put forward here are also in motoring mode - further work will be to implement the control in a full electromechanical system with torque from the turbine, wind resistance and blade angle control, mechanical iniertia and frictional losses in the gearbox.

In the next section a variety of results from the simulations are put forward for the conventional DTC method and the proposed method. This takes the form of different step changes in speed over a $0.2 \mathrm{~s}$ time period.

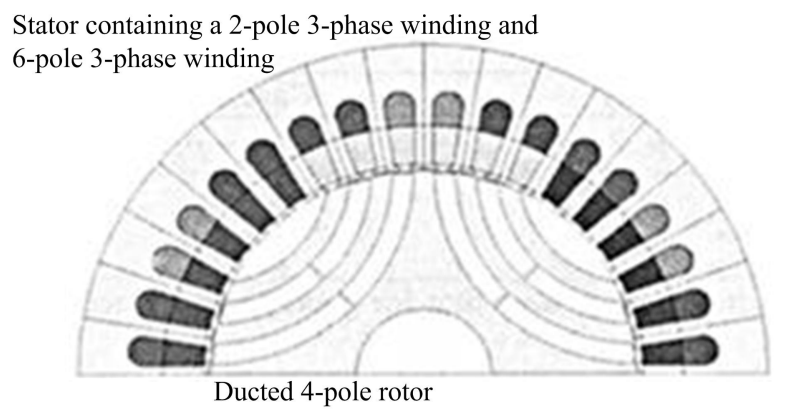

Fig. 5. 2-6-4 ducted pole rotor.

TABLE I. SimUlation Motor DETAILs (DimENSIONS IN MM).

\begin{tabular}{|l|l|}
\hline Pole Combination & $p_{\mathrm{g}}=6 p_{\mathrm{s}}=2 p_{\mathrm{r}}=4$ \\
\hline Grid frequency & $50 \mathrm{~Hz}$ \\
\hline Grid rated voltage & $200 \mathrm{~V}$ (phase) \\
\hline Grid rated current & $9 \mathrm{~V}$ \\
\hline Primary resistance & $1.2 \mathrm{ohm}$ \\
\hline Primary inductance & $46 \mathrm{mH}$ \\
\hline Secondary resistance & $0.9 \mathrm{ohm}$ \\
\hline Secondary inductance & $87 \mathrm{mH}$ \\
\hline Mutual inductance & $62 \mathrm{mH}$ \\
\hline
\end{tabular}

\section{SimUlation RESUlts}

Using Matlab $\AA /$ Simulink $\AA$, the proposed DTC method was simulated. Many of the governing equations for the BDFRM are given in [10] and [11] and these can be referenced. Here the focal point is on the control. If one set of windings is connected to the grid ( $50 \mathrm{~Hz}$ here), which is termed the power winding, then the control winding is required to be connected to an inverter. In Fig. 6, the variation of the frequency of the control winding as a function of speed is given for the 2-6-4 and 4-8-6 machines. It can be seen that in both cases the supply is $50 \mathrm{~Hz}$ to the control winding at standstill.

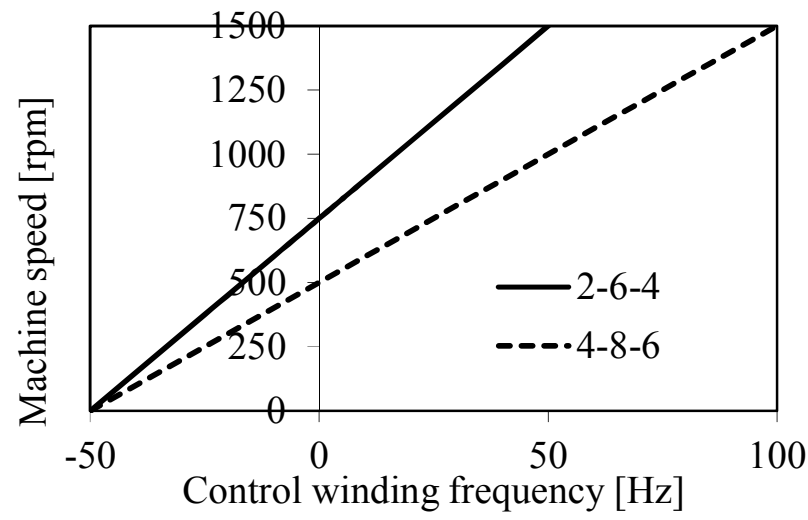

Fig. 6. Variation of control winding frequency with speed when power winding connected to $50 \mathrm{~Hz}$ grid. Two machines (2-6-4 and 4-8-6) are displayed.

A zero frequency point if found at $750 \mathrm{rpm}$ for the 2-6-4 machine and $500 \mathrm{rpm}$ for the 4-8-6 machine. This is similar to the synchronous speed in induction and synchronous machines. In fact the control windings can be shorted to form closed 
loops and the machine can start as an induction motor and can run up to the synchronous speed. In addition the control winding can be excited for a DC supply and synchronized to the grid so that it operates at the synchronous speed in a similar fashion to a synchronous generator. Here we operate in a variable AC drive mode where the control winding is actively excited from an inverter
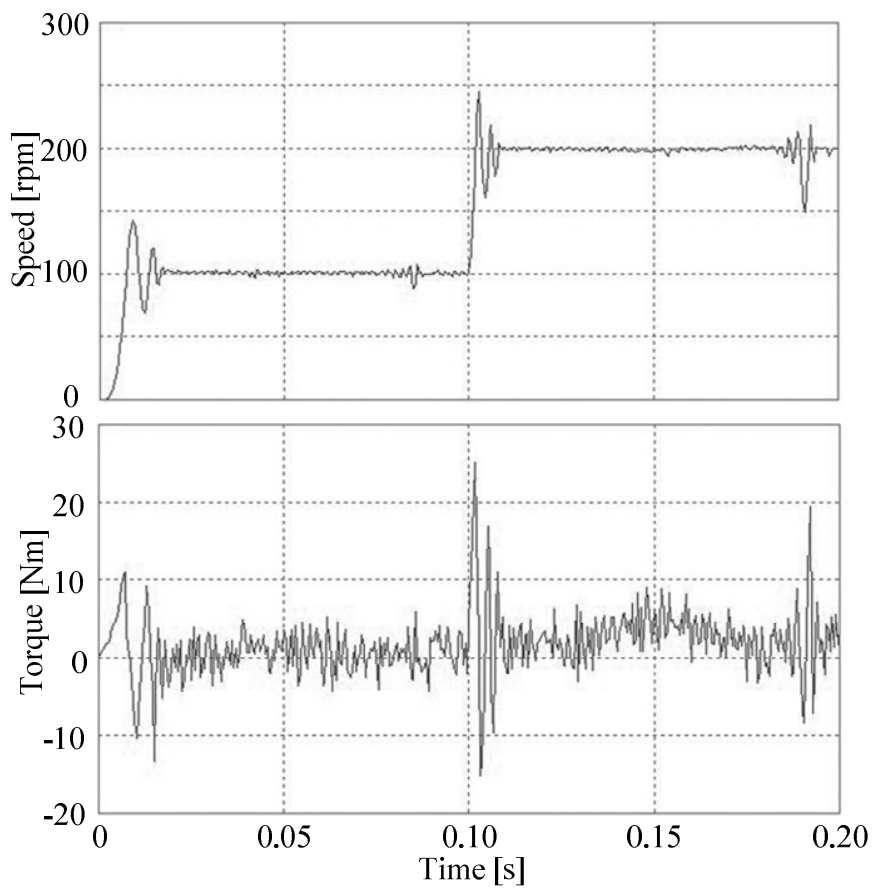

Fig. 7. Simulation results for changing speed setting from 0 to $100 \mathrm{rpm}$ to $200 \mathrm{rpm}$ based on the conventional DTC method.
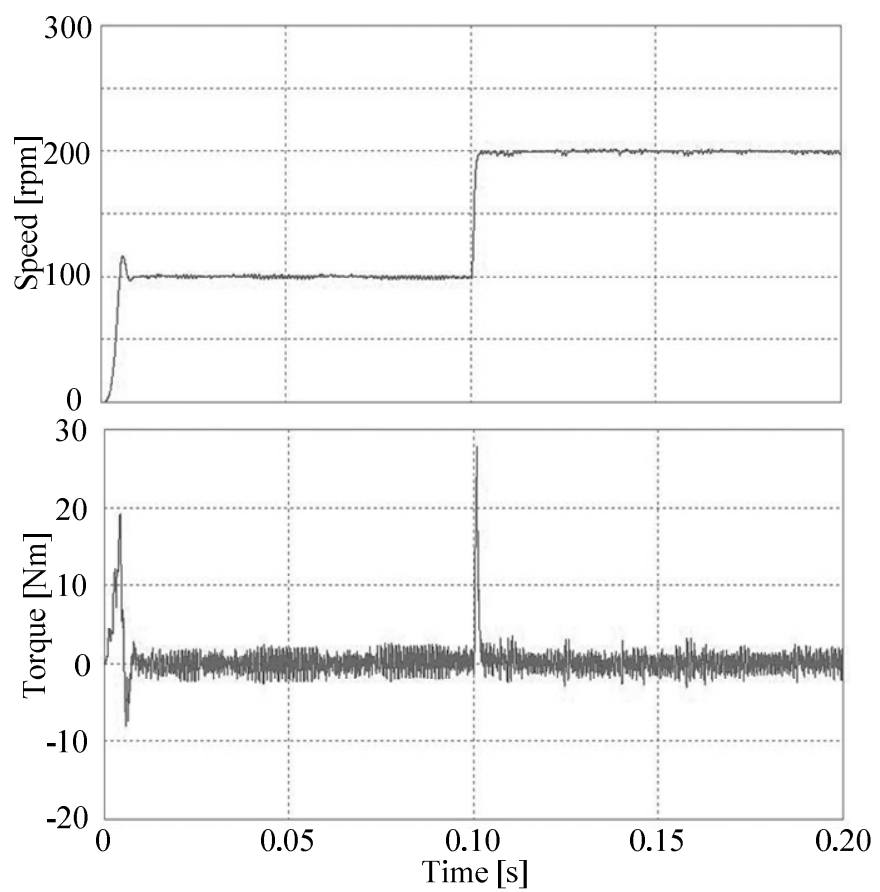

Fig. 8. Simulation results for changing speed setting from 0 to $100 \mathrm{rpm}$ to $200 \mathrm{rpm}$ based on the proposed DTC method.
In Figs. 7 and 8 the BDFRM speed is changed from 0 to $200 \mathrm{rpm}$ in two steps. This speed is below the synchronous speed and it can it be seen that the proposed DTC offers better control with improved torque response with reduced overshoot and oscillation when the correct speed is achieved. Since there is no load then the torque should be zero when steady state is obtained.
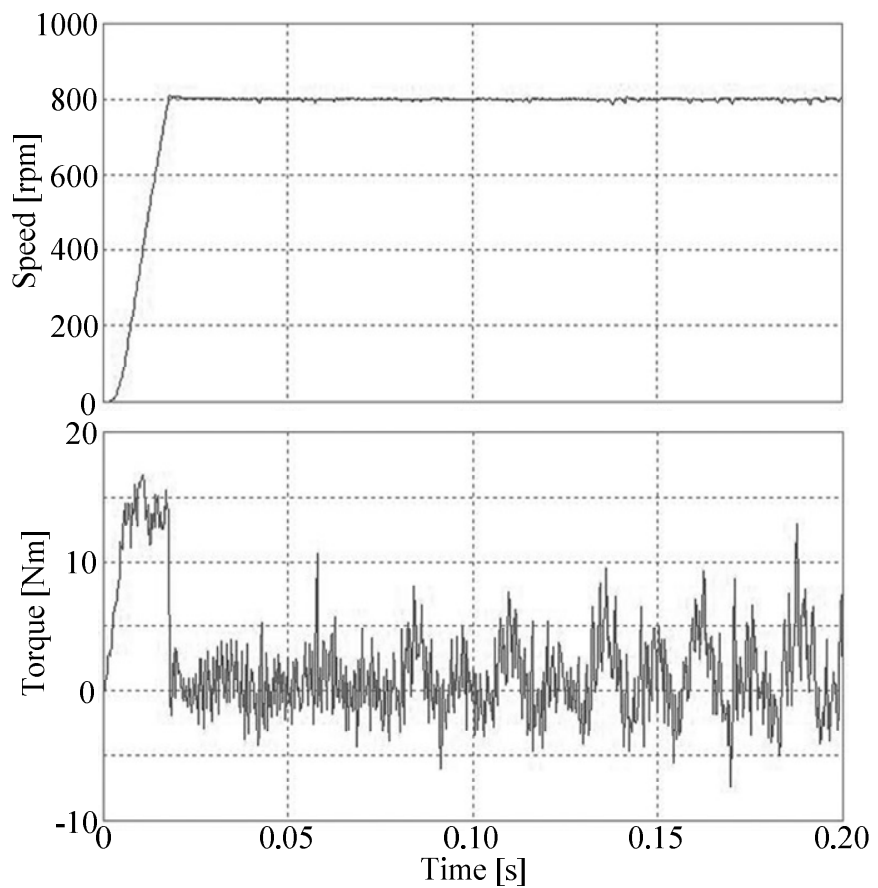

Fig. 9. Simulation results for changing speed setting from 0 to $800 \mathrm{rpm}$ based on the conventional DTC method.
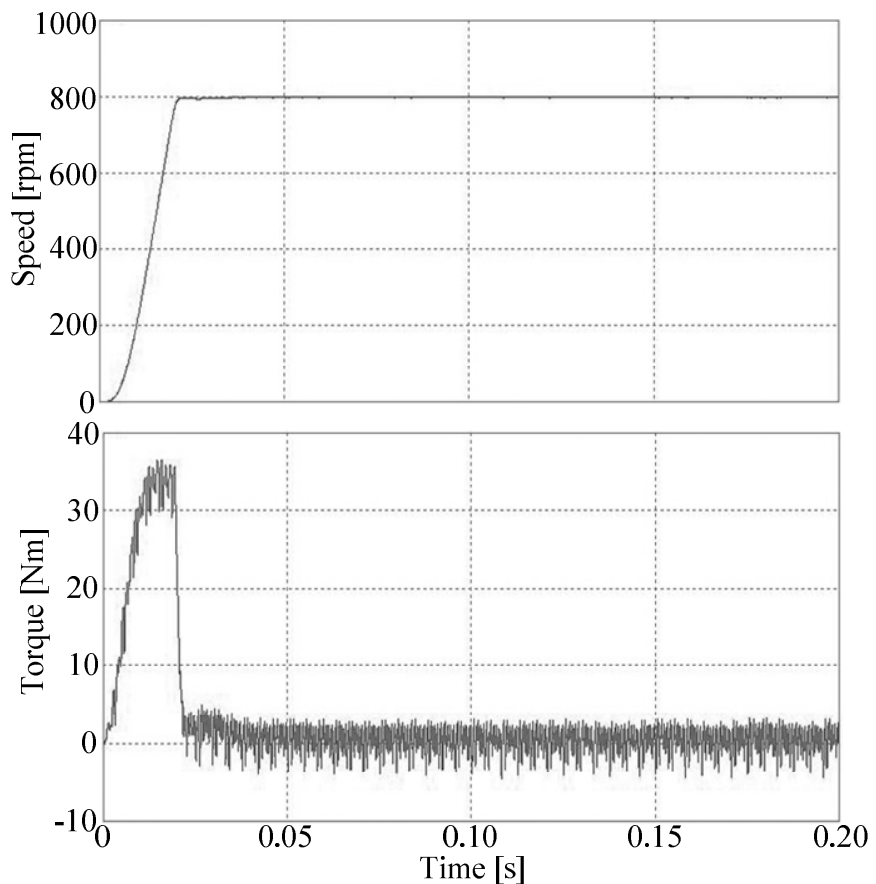

Fig. 10. Simulation results for changing speed setting from 0 to $800 \mathrm{rpm}$ based on the proposed DTC method. 
Comparison of the simulation results between the conventional DTC and the proposed DTC for a single step from zero to $800 \mathrm{rpm}$ are given in Figs. 9 and 10. This final speed is above the synchronous speed and it is found in both cases the simulation passes through this point with no problems. However, at $800 \mathrm{~Hz}$ the frequency in the control winding is only $3.33 \mathrm{~Hz}$ (from Fig. 6) so that both simulations show more torque oscillation around the target speed since the response to command will be more sluggish. The proposed method still shows improved response.

\section{CONCLUSION AND FUTURE WORK}

This paper suggests an improved DTC method for control of a BDFRM. The application is aimed at wind turbine generation. In order to reduce high torque and flux ripple that can be found with the conventional DTC method, this paper proposes the use of a Space Vector Modulation technique instead of the switching table selection technique. The suggested method has been successfully implemented and it is shown to reduce the torque and flux ripple to below those of the conventional DTC method.

This paper presents simulated validation of the proposed DTC method using SVM control of the BDFRM. While it is in terms of motoring mode operation it is equally valid for wind turbine generation and further work will address this. The simulation results in this paper show clearly the advantages of the improved DTC theory compared with the conventional DTC method.

This paper should be treated as a first stage to the development of an improved DTC method of control for the BDFRM when used in a wind turbine. The experimental validation of the proposed method is currently under way using a prototype driver. Further development of this method is to include a speed sensorless technique and to assess the performance in a full system that includes the wind turbine mechanical system and the grid connection. A prototype machine has already been constructed as reported in [9] and this will be used in the drive development.

\section{ACKNOWLEDGMENT}

This work is sponsored by the Australian Research Council, grant number DP1096356. The authors are grateful for this.

\section{REFERENCES}

[1] A. M. Knight, R. E. Betz, and D. Dorrell, "Design and analysis of Brushless Doubly Fed Reluctance Machines," in Energy Conversion Congress and Exposition (ECCE), 2011 IEEE, 2011, pp. 3128-3135.

[2] L. Xu, B. Guan, H. Liu, L. Gao, K. Tsai. "Design and control of a highefficiency Doubly-Fed Brushless machine for wind power generator application" in IEEE Energy Conversion Congress and Exposition (ECCE), 2010 pp 2409 -2416.

[3] M. G. Jovanovic, R. E. Betz, Y. Jian, and E. Levi, "Aspects of vector and scalar control of brushless doubly fed reluctance machines," in Power Electronics and Drive Systems, 2001. Proceedings., 2001 4th IEEE International Conference on, 2001, pp. 461-467 vol.2.

[4] R. E. Betz and M. G. Jovanovic, "Theoretical analysis of control properties for the brushless doubly fed reluctance machine," Energy Conversion, IEEE Transactions on, vol. 17, pp. 332-339, 2002.

[5] W. R. Brassfield, R. Spee, and T. G. Habetler, "Direct torque control for brushless doubly-fed machines," Industry Applications, IEEE Transactions on, vol. 32, pp. 1098-1104, 1996.

[6] M. Jovanovic and Y. Jian, "A direct torque controlled brushless doublyfed reluctance machine drive system," in Industrial Electronics, 2004 IEEE International Symposium on, 2004, pp. 917-922 vol. 2.

[7] P. S. Babu and S. Ushakumari, "Modified Direct Torque Control of induction motor drives," in Recent Advances in Intelligent Computational Systems (RAICS), 2011 IEEE, 2011, pp. 937-940.

[8] B. Lang, J. Yang, and W. Liu, "Research on Space Vector Modulation method for improving the torque ripple of Direct Torque Control," in Computer Design and Applications (ICCDA), 2010 International Conference on, 2010, pp. V3-502-V3-506.

[9] A. M. Knight, R. E. Betz, W. K. Song, and D. G. Dorrell, "Brushless doubly-fed reluctance machine rotor design," in Energy Conversion Congress and Exposition (ECCE), 2012 IEEE, 2012, pp. 2308-2315.

[10] R. E. Betz and M, Jovanovic, Introduction to Brushless Doubly Fed Reluctance Machines - The Basic Equations, Technical Report: EE0023, University of Newcastle, NSW, Australia, available at: $\mathrm{ftp} / / / \mathrm{vcs} 2$.newcastle.edu.au/Papers/BDFRM-Review.pdf.

[11] M. Jovanovic, J. Yu and E. Levi, "Direct Torque Control of Brushless Doubly Fed Reluctance Machines," Electric Power Components and Systems, Vol. 32, Iss. 10, 2004pp. 941-949. 